\title{
Towards Guidelines for Designing Augmented Toy Environments
}

\author{
Steve Hinske \\ Institute for Pervasive Computing \\ ETH Zurich, Switzerland \\ +41446320768 \\ steve.hinske@inf.ethz.ch
}

\author{
Marc Langheinrich \\ Institute for Pervasive Computing \\ ETH Zurich, Switzerland \\ +41446320688 \\ marc.langheinrich@inf.ethz.ch
}

\author{
Matthias Lampe \\ Institute for Pervasive Computing \\ ETH Zurich, Switzerland \\ +41446327123 \\ lampe@inf.ethz.ch
}

\begin{abstract}
Combining interactive technology with traditional toys promises to significantly enhance the educational value of children's play. Designing such augmented toy environments, however, requires designers to take both the traditional, technology-less nature of the toy, and the novel interactive aspects of the newly accessible virtual environment into account. This article attempts to present a unified set of guidelines for the design and implementation of augmented toy environments, drawing upon existing literature in traditional and educational toy and game design, as well as our own experiences in building mixed reality game environments. We also offer practical advice on the use of these guidelines by reporting on our own augmented toy environment for young children, called the Augmented Knight's Castle, which encourages learning about the Middle Ages in a playful way.
\end{abstract}

\section{Categories and Subject Descriptors}

H.1.2 [Models and Principles]: User/Machine Systems - Human factors. H.5.2 [Information Interfaces and Presentation]: User Interfaces - Haptic I/O, Prototyping, Theory and methods.

\section{General Terms}

Design, Experimentation, Human Factors, Theory.

\section{Keywords}

Design Guidelines, Augmented Toy Environments, Mixed Reality, Interactive Systems, Pervasive Computing

\section{INTRODUCTION}

Playing is an essential part in children's process of growing-up: Besides being a recreational amusement, it also serves as an important function for the psychological, physiological and social development of children [6][40]. Through playing "children learn about themselves, their environment and the people around them. As they play, children learn to solve problems, get along with other people and control their bodies as they enrich their creativity and develop leadership skills” [1].

Computer and video games typically fall short in supporting these benefits of traditional playing: Children sit isolated in front of a screen without being physically and socially challenged; they are absorbed into virtual worlds and detach themselves from the real world for many hours. Critics argue that prolonged exposure to video games can significantly limit or even diminish children's physical capabilities and social skills. Intense video gaming is also often linked to psychological disorders, such as increased violent behavior, obesity, neglect of relationships, and loss of reality [2][14][16][50].

Yet with all their drawbacks, computer and video games continue to appeal highly to both younger and older children alike. With today's sophisticated technology, video games can often create incredibly immersive and fantastic environments, being only limited by the creators' and players' imaginativeness. Due to the interactive nature of video games, gameplay itself can offer equally intricate designs, providing mental challenges that can constantly adapt to the players' skills.

Combining these two worlds - the real world and the virtual world, traditional games and interactive computer games - yields a thrilling and interesting symbiosis that might prove very beneficial for children. According to Stapleton et al., the ideal entertainment and learning experience in such mixed reality play environments and games then comes from the combination of physical experience, virtual content, storytelling and the imagination of the user [42][43] (see Fig. 1).

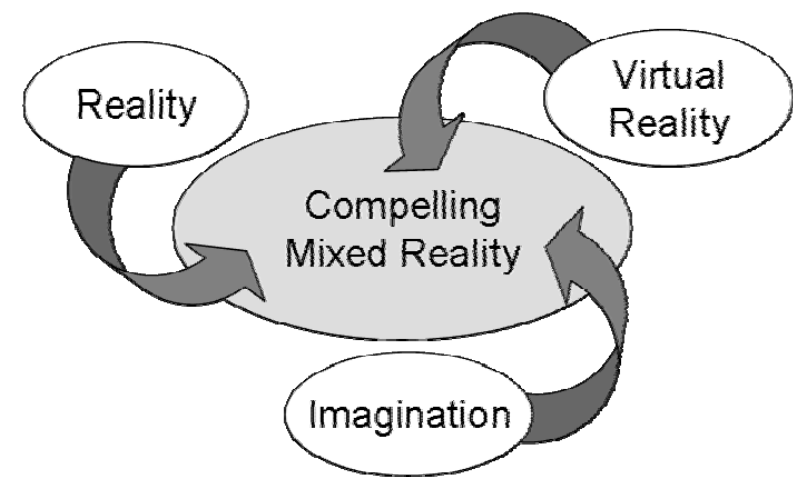

Figure 1: Compelling Mixed Reality [43]

Augmented toy environments try to achieve this promising though not trivial goal. By using pervasive computing technologies, i.e., embedded computing devices, miniature 
sensors, and wireless communication technology [28], augmented (or, smart) toy environments are a form of mixed reality entertainment that inspire the fantasy of children by enriching traditional toys with multimedia content [19]. Embedding technology into traditional game artifacts enables physical objects to be seamlessly connected to virtual content, which offers many interesting possibilities, especially for educational toys [9]. As stated by Bruner, learning seems best to be done in a playful way - this applies to children as well as to adults [5]. Such smart toys can also facilitate the social skills development of children with social disorders or mental diseases such as autism, and even help detecting them [29].

Creating augmented toy environments, however, is not just about putting some technology into a traditional toy. It is rather the design and implementation of an interactive system for children that takes both the traditional, technology-less nature of the toy, and the novel interactive aspects of the newly accessible virtual environment into account, combining both into a demanding mixed reality toy for entertainment and education.

Game conception and artifact design for augmented toy environments is thus a very challenging task, as designers have to take a much wider range of issues into account. Unfortunately, so far only few formal design methods for such mixed reality environments exist, such as the "Miyamoto Box" [3]. This article reviews and summarizes the current state-of-the-art in augmented toy environment design, and tries to develop a set of design guidelines to aid designers and researchers in this novel field.

Section 2 reviews relevant literature and reports on our own experiences in creating augmented toy environments, summarizing them into four sets of guidelines for designing traditional, augmented, tangible, and educational toys, respectively. Section 3 then describes how we took these guidelines into account when designing the Augmented Knight's Castle (AKC) [24], an augmented toy environment for young children that encourages learning about the Middle Ages in a playful way. We conclude in section 4 with a summary and a discussion of our experiences.

\section{DESIGN GUIDELINES}

The overall goal of game or play design is typically good "gameplay", a term that has been coined by game designers almost three decades ago, even though it continues to represent a rather vague concept [55]. Game design should be user-centered inasmuch as that the "game designer doesn't directly author gameplay experience, but rather creates global interaction rules and gameplay tools to help the player discover and create his own gameplay experience" [54]. Especially video games often address this aspect only insufficiently, if not neglecting it completely, by putting too much emphasis on technology. As Thackara politely puts it: "Many [...] know how to make amazing things, technically - but are often at a loss to understand what to make" [45].

Ideally, the focus of games and toys should be towards interactivity and user experience: Fun, immersion, engagement, physical and mental challenges, emotional stimuli, socializing, and creativity have been identified as primary goals in game design (e.g. [19]). Winograd challenges designers of interactive systems to move from interface design to interaction design: "Design thinking as a whole has to focus on the interaction" [52].
We thus approach the design of augmented toy environments from two angles: We begin in section 2.1 with the general requirements for designing stimulating and engaging toys, and then examine the integration of technology with its novel means for interactivity in section 2.2. Section 2.3 looks into additional challenges stemming from the design of tangible user interfaces as means for interacting with augmented toy environments, while section 2.4 takes the aspect of learning into consideration.

The resulting guidelines are summarized in tables in section 3.2 where we then demonstrate the application of these guidelines.

\subsection{Designing Toys}

Toys often resemble objects used in the adult world (e.g., tools such as a hammer, a car, or an entire household) and children imitate their usage by what they have been taught or perceived themselves. "Toys $[\ldots]$ have an exciting role in helping children to become mature, confident and imaginative adults." [1]. Thus, children should be able to easily perceive and understand the inherent role or function of each play object based on its physical appearance.

Judy Ellis from the Toy Design Program at the Fashion Institute of Technology states that "a really great toy invites discovery, enhances a child's play environment, and is fun, educational, and age appropriate" [25]. Furthermore, she points out that designers "must address both artistic and practical matters and learn to be mindful of financial, safety, and creative concerns".

The "Let's Play!” projects at the University of Buffalo formulated a number of universal design guidelines for toys [49]:

- The toy must be appealing: The design should communicate all necessary information effectively and appeals to children’s sensory abilities.

- It should be clear how to play with the toy: A simple design with well-defined access areas that offer consistent responses makes a toy easy to use, regardless of the children's experiences.

- The toy is adjustable for a range of users: For example, children can use the toy in a variety of positions (sitting, standing, playing on the floor, etc) or the output is varied and adjustable. Furthermore, the toy appeals to children at varying ages, developmental levels and abilities.

- The toy supports the child's development: Toys should encourage imagination and social play, stimulate physical or mental activity, and promote the discovery of new ways to play.

Hengeveld et al. [17], in studying the design of adaptive and interactive toys for very young handicapped children, come up with similar guidelines for designing complex interactive products, contrasting them in particular to the design of traditional computer- and video-based games:

- Social Interaction: Interactive toys should stimulate interpersonal interactions.

- Tangibility: By stimulating multiple senses and skills, affording both actions and play, interactive real-world toys offer more room for social, personal, and active interaction, as well as a slower pace and more involvement. 
- Challenge: In order for children to learn, they need to be motivated. Challenge is a key element of motivation. Toys should engage the child by stimulating it to reach for the "boundaries of its skills". Interactions should be appealing, rewarding, engaging and fun.

- Adaptivity: Toys that adapt to the individual child optimize the learning setting and avoid frustration. Supporting such adaptability requires advanced technologies, such as embedded intelligence, wireless networking, and interactive, adaptive narratives.

- Design: Products should "resonate with young children," and in their specific case appeal to both challenged and able-bodied children.

Based on our experiences when building and evaluating augmented toy environments, especially in the hands of young and active children, we can add the following guidelines that might more or less be seen as "common-sense":

- Toys must be reliable and durable. This specifically applies to augmented toys that might contain highly sophisticated (and often delicate) technology.

- Toy environments are highly dynamic by nature with toys added and removed constantly. Any computer-controlled interactive component must be able to adjust quickly and robustly to changes in the gaming environment.

- Augmented toy environments should provide immediate feedback. Rogers et al. note that "a crucial feature is to ensure that there is immediate feedback, with as little delay as possible between the performance of an action and the perception of its effect (as happens with everyday physical to physical transforms)" [33].

- Designers should respect the children's intelligence by creating adaptive and age appropriate toys. This includes avoiding the design of toys that contradict or are inconsistent with the real world (e.g., a toy dog that says "Hello" [13]).

- As pointed out by several authors, a very important aspect when developing (designing and building) such systems is the early involvement of children in this process (e.g., [11][23]).

Tab. 1 in section 3.2 summarizes the guidelines of this section.

\subsection{General Thoughts about Integrating Technology into (Traditional) Toys}

Embedding technology into physical objects and into the environment to support the users is a fundamental part of the pervasive computing vision [28]. The idea is to integrate the technology in such a way that it figuratively disappears and the user can thus shift the attention to the task at hand instead of focusing on the computer [51]. Though a "technology-inspired" approach can also be very successful sometimes [34], we follow the pervasive computing vision and assemble the following set of general requirements:

- Provide added value through technology: Enhancing traditional toys with technology should not be a goal in itself, but should offer clear benefits. Wren and Reynolds
[53] suggest adding "as little as possible, but as much as necessary.” Rogers et al. [34] point out that technology should closely follow the specific activities that are to be supported or realized (e.g., looking for or identifying something; using something to cause an effect; viewing or listening to something; collecting things).

- Technology should stay in the background: The augmentation should not lead children to focus on the added features only. Technology should not let children neglect the traditional play and limit their own imagination. Note that users might change their behavior after they have gotten used to the technology. Rogers et al. point out that "if we want to promote seamless continuity between the physical and the virtual, while at the same provoking wonder, then we may need to design an interactive environment where novelty is appropriately embedded in familiarity” [34].

- Design for implicit interactions [36]: To prevent a distraction from the toy itself, the integrated technology should be unobtrusive, or even completely invisible, allowing children to focus on playing with the toy instead of using the toy's novel interfaces.

- Strive for robustness in the presence of failures: The toy environment should still be functional if the technology fails or is switched off; i.e., the technology should not become critical to the play experience and render the environment useless if it is malfunctioning or turned off.

Similar to computer games, the creation of mixed reality games or play environments involves two aspects, the (game and interface) design and the (hardware and software) development. Good "synchronization schemes" are crucial to a successful design [55].

Equally important is an iterative development process and extensive testing to avoid systems that are too difficult to use, or that do not meet certain essential deployment criteria (e.g., robustness, safety). This might especially be true for initial prototypes of novel games or toys: "Games are extremely timecritical and unlike applications software, require high fidelity prototypes - a slow primitive prototype [...] cannot faithfully represent the gameplay of the real game and its usefulness is questionable at best" [55]. In addition to that, the embedding of technology into toys requires the designer to expect (and be able to cope with) contingencies: Technology, particularly if novel, tends to behave in unanticipated ways or can be used in an unforeseeable fashion.

In our experience, this problem is difficult to overcome, especially when designing play environments for children at elementary school age. We recommend fast prototyping (the first draft is usually based on intuition and personal experience) and early testing with the target user group, and to then iteratively extend and improve the prototype based on the feedback of this group (also cf. [31][37]). Usually, an iterative design approach combined with "play testing" phases should be employed to reach a solid game or play [8].

Tab. 2 in section 3.2 summarizes the guidelines discussed in this section. 


\subsection{Tangible User Interfaces}

Physical objects with integrated technology to control and interact with computers are called tangible user interfaces (TUIs) [21], a sub-field of human-computer interaction $(\mathrm{HCI})^{1}$. Tangible user interfaces "augment the real physical world by coupling digital information to everyday physical objects and environments", taking "advantage of natural physical affordances to achieve a heightened legibility and seamlessness of interaction between people and information" [48]. Augmented toys can be seen as a specific form of a TUIs, thus experience from TUI design might be beneficial for creating augmented toy environments. TUIs might also form a higher level interfaces to smart toys, providing access to configuration and management options not directly related to gameplay.

Although there has been a considerate amount of research on TUIs in recent years, Stringer et al. note that "tangible thinking", which refers to the "dynamic structure in the real-world space, is still at its infancy" [44] and experiences and guidelines for graphical user interfaces (GUIs) are often not applicable to TUIs. The following paragraphs will list several guidelines for TUI design and discuss their applicability to augmented toy environments. And, despite all the more design-oriented requirements, it is essential to remember that TUIs are still a form of HCI and that "much of the structure of this interaction derives from the technology" [7].

Terrenghi lists several important features to keep in mind when designing TUIs [47]:

- Allow for 3D-space manipulation (if possible), enabling different kinds of actions and feedback from those actions.

- Use of spatially multiplexed input to interact with virtual objects.

- Continuity of action and richness of manipulation vocabulary in input, as distinct from discrete actions or gestures afforded by mouse and keyboard.

- Direct spatial mapping between input and output so that an action produces feedback at the point where input is sensed.

- Rich multimodal feedback (not limited to visual and audio feedback), such as it is possible in the physical world.

- Physical constraints, which affects users' mental model of the possible manipulations with an artifact.

Similarly, Shaer et al. present essential aspects of TUIs [38]:

- Multiple behaviors: When specifying the behavior of a certain physical object the designer is required to take into consideration the mutual impact of physical objects.

- Multiple actions: In contrast to GUIs where there are six fundamental interaction tasks (cf. [12]), in a three dimensional space of the physical world there are numerous activities that can be performed with, or upon, any physical object (e.g. squeeze, stroke, toss, push, tap, pat, etc.).

\footnotetext{
${ }^{1}$ Since our focus is on children, it is worth mentioning that there exists another sub-field of HCI called child-computer interaction (CCI), e.g., [27]. This research branch, however, focuses more on general (e.g., psychological and social) issues of how children interact with computers.
}

Hence, the designer is charged with selecting and defining the meaningful actions.

- No standard I/O: For example, measuring movement of an object may be implemented using magnet sensors, RFID or computer vision. Though identical in purpose, each technology currently requires a different set of physical devices, instructions, and code.

- Continuous interaction: TUIs support a combination of discrete and continuous interaction. When users continuously interact with physical objects, they perceive that their motions are directly mapped to changes in the digital information. However, existing event-based models for designing interactive systems currently fail to capture continuous interaction explicitly (cf. [22]). Thus, TUI software developers are often required to deal with continuous interaction in considerably ad-hoc, low-level programming approaches.

- Distributed interaction: In a tangible user interface there is no single point of interaction, as multiple users can simultaneously interact with multiple physical objects (also cf. [10][20]). In addition, the same action in a given interaction may be distributed across multiple physical objects. Existing models for designing interactive systems usually handle multiple input devices by serializing all input into one common stream. However, in TUIs this method is less appropriate, since the input is logically parallel and the users' perception is that two or more dialogues are taking place simultaneously.

Antle proposes the CTI framework for the design of tangible (not necessarily technologically enhanced) systems for children [4]:

- Space for action: Unlike traditional desktop systems which utilize an indirect controller (e.g., mouse), tangible systems afford opportunities to capitalize on children's developing repertoire of physical actions and spatial abilities for direct system input and control.

- Perceptual mapping refers to the mapping between the perceptual properties (often appearance) of the physical and digital aspects of the system (relationship between how things appear and how they respond). Thus, designed affordances need to consider the age-appropriate perceptual, cognitive and motor abilities and limitations of children (also cf. [46]).

- Behavioral mapping is the mapping between the input behavior and output effect of the physical and digital aspects of the system. Design requires consideration of children's understanding of how things behave.

- Semantic mapping refers to the mapping between the information carried in the physical and digital aspects of the system. Design requires consideration of children's understanding of what things mean in various representational forms.

- Space for friends: Tangible and spatial computer-mediated systems have both the space and the affordance for multiple users.

Tab. 3 in section 3.2 summarizes the design guidelines for tangible user interfaces for toys. 
Before we come to design guidelines for educational playing, we would like to add one final comment on TUIs with regard to the aforementioned iterative design approach: Based on earlier work by Norman [30] and Soloway et al. [41], Stringer et al. come to the conclusion "that TUIs are particularly well-suited to a process of frequent, incremental and iterative design. This is because many of the most important aspects of a TUI - those around integration with the physical context of use - can be tested using low-tech prototypes which can be built quickly and cheaply” [44].

\subsection{Educational Aspects}

While the potential of learning while playing computer or video games has already been widely investigated (e.g. [15][32]), learning in mixed reality environments has not been largely explored yet.

Schaller, extending previous work by Malone and Lepper [26], identifies six key aspects of successful learning systems [35]:

- Challenge: Clear, fixed goals that are relevant for the learner can offer motivating challenges. Feedback on performance should be frequent, unambiguous, and supportive. Lastly, the activity should promote feelings of competence for the person involved.

- Curiosity: Schaller describes two different forms of curiosity - sensory curiosity and cognitive curiosity. Audio and visual effects, particularly in computer games, may enhance sensory curiosity. When learners are surprised or intrigued by paradoxes, or incompleteness, it arouses cognitive curiosity.

- Control: Learners prefer feelings of self-determination and control. The ingredients of contingency, choice, and power contribute to the control feature of the learning experience.

- $\quad$ Fantasy: The emotions and thinking processes of the learner form the basis for fantasies, which should appeal not only to the emotional needs of learners, but should provide relevant metaphor or analogies.

- Iteration: Repetition is vital to learning. Whether it consists of small iterations within the activity sequence, or replaying the entire game to attempt alternate strategies, iteration supports the learning process by encouraging experimentation, hypothesis testing, and synthesis.

- Reflection: Ideally, reflection should happen during iterations, as players test new hypotheses and synthesize the outcomes with their existing understanding.

Tab. 4 in section 3.2 recapitulates these design guidelines on educational aspects.

\section{APPLYING THE DESIGN GUIDELINES}

In this section we attempt to bridge the gap between the theoretical guidelines presented in section 2 and how to put them into practice. To this end, we first introduce the Augmented Knight's Castle (AKC), an augmented toy environment based on the Playmobil Middle Ages scenario.

This interactive mixed reality platform for children in elementary school age aims at enhancing the entertainment factor and furthermore encourages the kids to learn about the Middle Ages in a playful way. We then look into how our implementation meets the accumulated design guidelines. This includes discussing our work and also pointing out future work to further improve the Augmented Knight’s Castle.

\subsection{The Augmented Knight's Castle}

We realized these ideas by implementing an augmented toy environment, the AKC (see Fig. 2) [24]. The environment enriches the children's pretend play by using background music, sound effects, verbal commentary of toys figures, and different forms of tactile and visual feedback in reaction to the children's play.

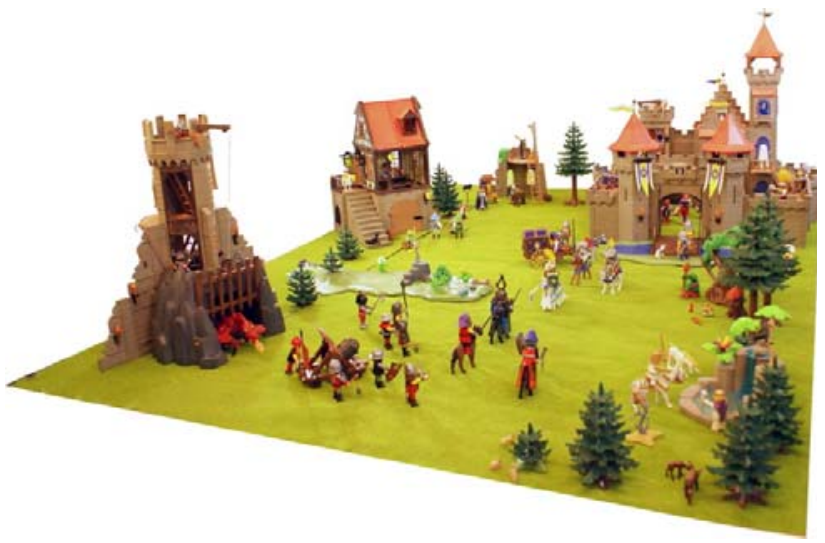

Figure 2: The Augmented Knight's Castle

The environment consists of the Playmobil Knight's Castle and other buildings and figures that have been equipped with radio frequency identification (RFID) technology to enable the unambiguous and unobtrusive identification and tracking of tagged play figures and objects. The RFID tags of different sizes are attached to or incorporated into the pieces of the playset to uniquely identify them (see Fig. 3). To compensate for possible false negatives (i.e., a figure is not read although being on an antenna), we tagged most objects with several tags of different orientation (e.g., back and bottom side of figures) to have at least one of the tags read in an antenna field. The ID that is stored on the RFID tag is used as the key to map the play objects to their virtual information such as name, images, stories or sounds.

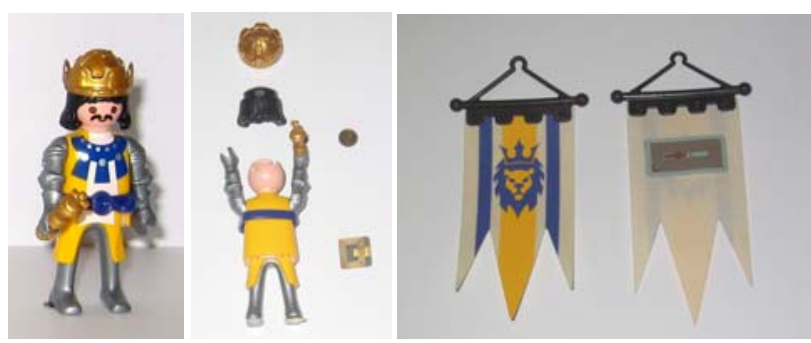

Figure 3: Unobtrusive integration of RFID technology (tags)

The RFID antennas are either attached to toy buildings or to different types of floor elements such as the fairy spring, to detect the presence of toy pieces in their proximity (see Fig. 4 for an example of a scene with hidden and disclosed RFID antennas, respectively). Based on the aggregated data gathered by the antennas, the sounds and commentaries are played accordingly (e.g., the dragon roars when leaving its dungeon or a fanfare resounds when the king enters the inner yard of his castle). 


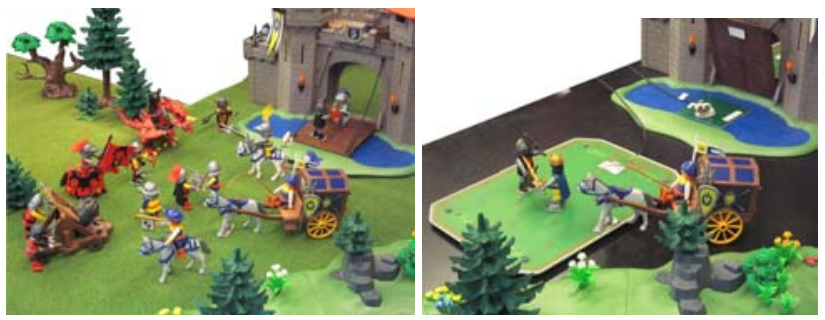

Figure 4: A scene with RFID antennas hidden (left) and disclosed (right)

In addition, smart toys, i.e., toys with integrated acceleration sensors for gesture recognition and a mobile RFID reader, have been added to the environment to stimulate even more forms of interaction with the play set (e.g. a bottle of magic potion). To this end, we employed mobile RFID readers and embedded them into different toys to enable them as touch-me devices (see Fig. 5). To further allow other forms of interaction, we attached a sensor board that includes, among others, light and a 3Dacceleration sensor. The acceleration sensor can be used to perform gesture recognition such as shaking the magic bottle or a circular movement with the magic wand.
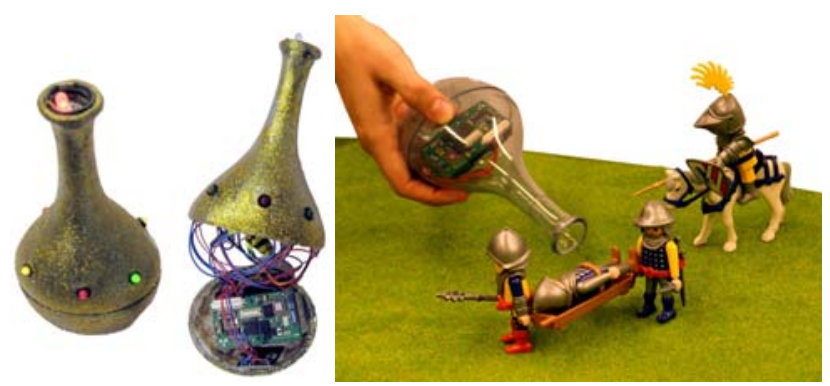

Figure 5: The magic bottle

Moreover, utilizing the location-awareness of the play set and the semantic mapping of the play objects [18], the AKC allows integrating learning experiences for the children into the play, i.e., children can learn more about the Middle Ages in a playful way. The environment can be enabled to teach foreign languages, e.g. by pointing with a magic wand on figures or buildings.

Individual play figures teach children about their profession and tasks and their life and role in the Middle Ages depending on their context in the play. The king, for example, tells short stories about living with his family and court in the castle, including topics such as the royal family, craftsmen and guilds, weaponry or heraldry (see Fig. 6). Another example is the troubadour who teaches songs and poems and sings together with the children.

In addition to the location-awareness (e.g., the smith is in the inner yard), we can also exploit time and the children's interaction with individual figures: A figure can, for example, invite children on a quest if there has not been much activity for a while. Or, since we store the location-aware information, a figure could verbally complain if placed at a certain place for a second time (e.g., a knight is again put in the dungeon and sighs "Oh no, not the dungeon again...”).

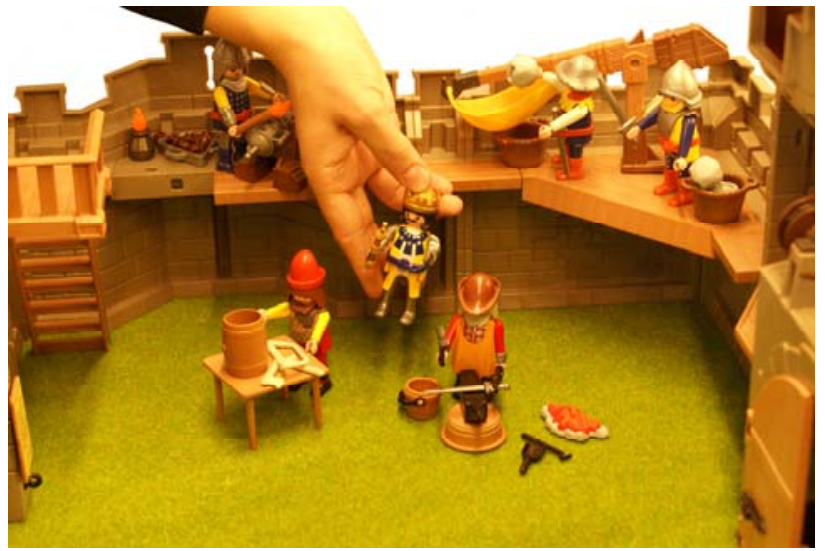

Figure 6: The king explains the castle and how people lived in the Middle Ages

We now examine how the AKC meets the presented design guidelines. The purpose of this section is to give the reader an idea of what each guideline means and implies when put into practice. Note that we do not describe the AKC in detail here since this would exceed the scope of this paper.

\subsection{Realizing the Design Guidelines}

In this section we apply the guidelines that we discussed above. To provide a structured and quick overview, we summarize the design guidelines in tables 1-4 and describe how we realized them as we go through each set of guidelines.

Table 1: Summary of design guidelines for (traditional) toys

1.1. Emphasize fun and provide good "gameplay” [55][25].

1.2. Offer mental challenges [25][17][49].

1.3. Adapt to the toy to the target users (incl. age-appropriate and respect the children's intelligence) [25][17][49][13].

1.4. Make the toys reliable (i.e., it always works), durable (i.e., long-lasting), and safe (e.g., no sharp edges) [25].

1.5. Support social interaction [17].

1.6. Support physical experience (i.e., tangible) [17].

1.7. The toy should be easy to understand and simple to use [17][49].

1.8. Encourage the children's imagination and story-telling.

1.9. Supply immediate feedback.

1.10. Let the toy extend the children's playground and let it support the high dynamics of such environments (cf. [49]).

1.11. Integrate children in design process [11][23].

Most of the guidelines of the first set are inherently met due to the shape and appearance of the toys (as designed by Playmobil). We can thus consider the guidelines 1.1, 1.3, 1.4, 1.5, 1.6, 1.7, 1.8, 1.10 to be sufficiently realized. Guidelines 1.2 (mentally 
challenging) and 1.9 (immediate feedback) will be dealt with when discussing the integration of technology and the learning environment.

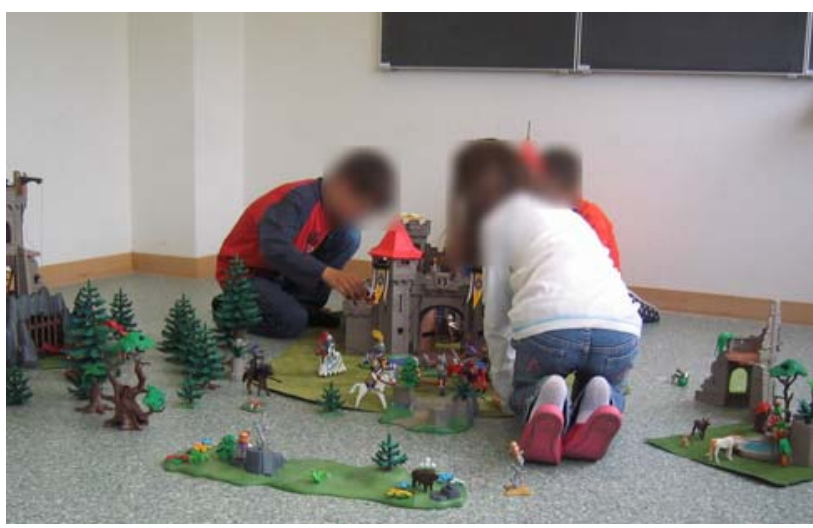

Figure 7: Children playing with the first version of the AKC

As far as guideline 1.11 is concerned, we have to admit that we initially did not include children in the design process (e.g., when designing the smart toys); we considered it too difficult to convey our idea of an augmented toy environment to children. Therefore, we decided to first build a prototype and then ask for feedback (also see guideline 2.10). After having completed an initial prototype, however, we invited some children to play with our environment (see Fig. 7) and integrated our findings in the process of improving and extending the AKC. A much larger user study will be conducted in the near future.

Table 2: Summary of design guidelines for integrating pervasive computing technology into (traditional) toys

2.1. The technological enhancement must have an added value.

2.2. Specify what actions / tasks are to be supported [34].

2.3. Let the focus should remain on the toy and the interaction itself, not on the technology.

2.4. Integrate the technology in such a way that it is unobtrusive, if not completely invisible.

2.5. Toys should be still usable (in the "traditional” way) even if technology is switched off or not working.

2.6. Tightly intertwine design and implementation [55].

2.7. The technology should be reliable, durable, and safe (cf. guideline 1.4)

2.8. Offer immediate and continuous feedback (cf. guideline 1.9).

2.9. The added technology should support the high dynamics of play environments (cf. guideline 1.10).

2.10. Employ an iterative development process, including rapid prototyping and testing [55][31][37][8].
The second set of guidelines is equally well met by the AKC since there is a clear intention when integrating the technology: To increase the fun and incorporate educational content (see guideline 2.1). In order to meet guideline 2.2, we found the usage of UML use cases to be very helpful and suitable.

The technology is unobtrusively embedded in the environment and the toys (see Fig. 3 and 4) and thus, on the one hand, leaves the focus on the actual playing and interacting with the environment, and, on the other hand, remains operational in the traditional way if switched off or malfunctioning (guidelines 2.3, 2.4., and 2.5).

One aspect especially important to us was immediate and location-aware feedback (guideline 2.8): We integrated several loudspeakers in the environment so that the sound is played where the actual action is taking place (e.g., when the king enters the inner yard of the castle, the fanfares are played at this location).

Guidelines 2.7 and 2.9 are so far only insufficiently realized. Since we employ RFID technology to identify the play figures, we also have to cope with the inherent problems that can possibly arise using this technology (e.g., tags that are not read although in vicinity, etc.). As to the highly dynamic environment, we consider RFID technology to be very suitable to manage toys and play figures; this requires, however, newly integrated play figures to be also equipped with tags, which is not the case with current offthe-shelf products.

Table 3: Summary of design guidelines for tangible user interfaces in the context of augmented toys

3.1. Exploit the (3D) space when designing (meaningful) interactions; make use of the inherent richness of tangible interaction [47][38][4].

3.2. Enable continuous and seamless interaction by multiple possibilities of interaction and manipulation [47][38].

3.3. Spatially map input and output [38].

3.4. Provide rich multimodal feedback [47] (cf. guidelines 1.9 and 2.8).

3.5. The physical appearance should be consistent and meet the children's perceptual abilities and mental models (especially how things behave and how they are used) [47][4] [38] (cf. guideline 1.7)

3.6. Allow distributed interaction and shareable interfaces [38][10][20][4].

3.7. Design the toy (environment) with an indisputable and consistent semantic mapping [4][18].

The third set of guidelines brings us to the tangibility of the AKC. Guidelines 3.1 and 3.6 are apparently met: Since children can move around freely and most smart toys are mobile and allow 3dimensional interaction (e.g., gesture recognition with the magic wand). Furthermore, every child can use every toy and simultaneous interaction is supported and even encouraged.

We think that guideline 3.2 is also realized: The children can, for example, learn about a play figure (e.g., the king) by either using the magic wand (i.e., pointing with the wand at the king and a verbal commentary is played), the magic book (i.e., the king is 
placed on one side of the magic book and a short text about him is displayed on the other side using an embedded screen), or putting the object at a designated location (e.g., putting the king in the tower of the castle also triggers the audio feedback).

With the integration of several loudspeakers, one display (in the magic book) as well as tactile feedback in the magic wand and magic bottle through vibration modules, we certainly provide rich multimodal feedback (guideline 3.4, also see paragraph on guideline 2.8).

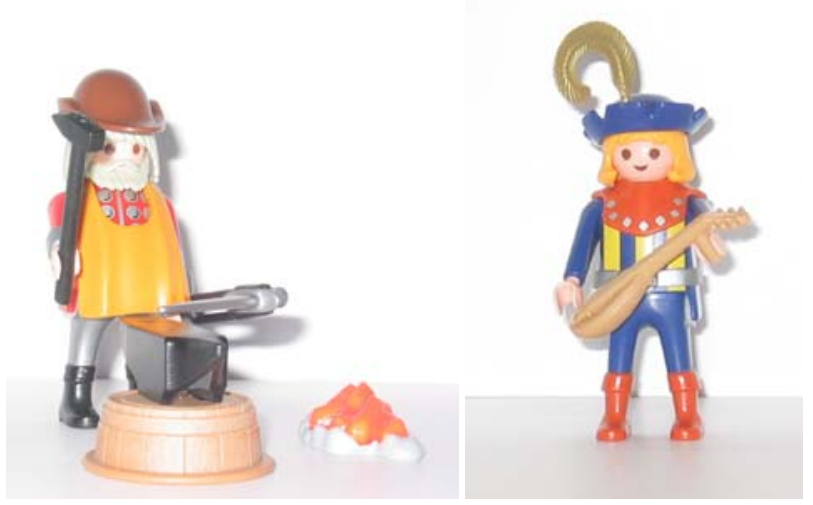

Figure 8: The smith (left) and the troubadour (right)

Guideline 3.5 is implemented by exploiting the inherent semantic mapping based on the physical appearance [18]: The smith can be easily identified as the smith, the troubadour as the troubadour, etc. (see Fig. 8). We also use this benefit for learning purposes: The alchemist, for example, can teach the children about chemistry and physics furthermore inform about the history and role of natural science in the Middle Ages.

\section{Table 4: Summary of design guidelines for educational toys}

\begin{tabular}{|c|}
\hline $\begin{array}{l}\text { Provide clear challenges and feedback. } \\
\text { Stimulate sensory and cognitive curiosity. } \\
\text { Allow the children to control the (learning) environment. } \\
\text { Support fantasy by relevant metaphors and analogies. } \\
\text { reflection (i.e., feedback; also cf. guidelines } 1.9 \text { and 2.8). }\end{array}$ \\
\hline
\end{tabular}

This brings us to the final set of guidelines. We only gave a brief introduction on our environment (for a far more detailed description see [24]), but it should have become apparent that the AKC aims at meeting all the guidelines of the educational set. Guideline 4.1, for example, is realized by playing sounds and verbal commentary based on where a child places a particular figure.

A figure could furthermore tell a child that if placed at a specific place, it could then explain more about a topic related to this place (e.g., the craftsman could say "If you position me at the drawing bridge, I can tell you how these were built”; also cf. Fig. $6)$. This does not only provide challenges and feedback (guideline 4.1), but also stimulates the child's curiosity (guideline 4.2) and fantasy (guideline 4.4).
This approach even allows for iteration of sequences including reflection (guideline 4.5): Another figure, for example, the commander of the king's knights, could ask the child to place him to the drawing bridge, where he will not explain then how they were built but how, thus bringing a new perspective and new information about the same object into the play. Since the children are empowered to always start and stop an educational tour through the medieval world, we realize guideline 4.3 in equal measure.

We currently plan to conduct a large user study on how well these guidelines are actually met.

\subsection{Future Work}

Though the AKC seems to implement most of the compiled guidelines quite well, a fair amount of work has to be done in order to yield a completely operational, not to mention marketable, platform. Section 3.2 also focused on examples where our environment meets the required criteria exceptionally well; but there usually are other components that do not meet a specific guideline to the same extent.

We particularly need to improve the smart toys to enable a more intuitive usage (semantic and behavioral mapping): The children were not always able to understand the meaning or function of the smart toys; e.g., the magic bottle was sometimes used to deliver a potion to a figure, and another time as a "magic lamp" inhabited by a jinn to satisfy a wish.

Besides sound effects, we also play background music and verbal commentaries that adapt to the current play situation. We are planning to further enhance the playing experience by adding light, scent, vibration, or other actuators through which the virtual can reach out to the physical reality.

\section{CONCLUSION}

In this paper, we presented our findings on designing augmented toy environments for interactive playing and learning for children. We compiled four sets of design guidelines for designing traditional, augmented, tangible, and educational toys, respectively. Based on the example of the Augmented Knight's Castle, an augmented toy environment for entertainment and learning, we then demonstrated how these guidelines can be practically applied.

Designing a truly thrilling augmented toy playset is a non-trivial and sometimes even cumbersome task: The goal is not a computer in a toy wrap but rather a (traditional) toy with imperceptible digital enhancements. Unfortunately, due to the novel and interdisciplinary nature of mixed realities environments, there are only a few design guidelines available yet; and, quite often, those available are too abstractly formulated to be of any practical value.

Though this area requires much further research, we hope that the guidelines presented and discussed in this paper are helpful to fellow researchers and designers and that they provide a vital step towards a general guideline for designing interactive augmented toy environments.

We are also confident that other disciplines might benefit from our work, since most of the guidelines are generally applicable to all kinds of augmented objects. Applying and possibly extending these criteria by looking at different scenarios and applications 
besides augmented toy environments might yield interesting results and advance the field of interaction design significantly.

\section{REFERENCES}

[1] American Toy Institute. 1994. The Toy Manufacturers of America Guide to Toys and Play, Revised Edition. DOI= www.eric.ed.gov/ERICWebPortal/recordDetail?accno=ED3 94625

[2] Anderson, C. A. and Bushman B. J. 2001. Effects of Violent Video Games on Aggressive Behavior, Aggressive Cognition, Aggressive Affect, Physiological Arousal, and Prosocial Behavior: A Meta Analytic Review of the Scientific Literature. Psychological Science 12(5), 353-359.

[3] Angle, R., and Dwyer, W. 2001. Effective Project Management. In Proceedings of Game Developers Conference.

[4] Antle, A.N. 2007. The CTI framework: informing the design of tangible systems for children. Proceedings of the 1st international conference on Tangible and Embedded Interaction (TEI), 195-202.

[5] Bruner, J.S. 1979. On Knowing, Cambridge, Mass., Belknap Press of Harvard University PressSystem

[6] Butterworth, G. and Harris, M. 1994. Principles of Developmental Psychology. Hillsdale, NJ: Lawrence Erlbaum.

[7] Carroll, J.M. 1997. Human-Computer Interaction: Psychology as a science of design. In Annu. Rev. Psychology, 48, 61-83

[8] Clanton, C. 1998. An Interpreted Demonstration of Computer Game Design. In Proceedings of Conference on Human Factors in Computing Systems (CHI '98).

[9] Dettori, G., Giannetti, T., Paiva, A. and Vaz, A. 2006. Technology-Mediated Narrative Environments for Learning. Sense Publishers.

[10] Dourish, P. 2001. Where The Action Is: The Foundations of Embodied Interaction. Cambridge, MA. MIT Press.

[11] Druin, A. 2002. The role of children in the design of new technology. In Behaviour and Information Technology, 21, 1, 1-25.

[12] Foley, D., Wallace, V. and Chan, V. 1984. The Human Factors of Computer Graphics Interaction Techniques. In IEEE Computer Graphics \& Applications, 13-48.

[13] Francis, A., and Mishra, P. 2006. Children's Understanding of and Interactions with Anthropomorphic Toys. In Proceedings of World Conference on Educational Multimedia, Hypermedia and Telecommunications 2006, Chesapeake, VA: AACE, 411-416.

[14] Funk J.B., Buchman D., Jenks J., and Bechtoldt H. 2003. Playing violent video games, desensitization, and moral evaluation in children. Applied Developmental Psychology, 24, 413-436.

[15] Gee, J.P. 2003. What Videogames Have to Teach us about Learning and Literacy. New York \& Houndmills: Palgrave Macmillan.
[16] Gentile, D.A., Lynch, P.J., Linder, J.R., and Walsh, D.A. 2004. The effects of violent video game habits on adolescent hostility, aggressive behaviors, and school performance. Journal of Adolescence, 27, 5-22.

[17] Hengeveld, B., Voort, R., van Balkom, Hummels, C., and de Moor, J. 2007. Designing for Diversity: developing Complex Adaptive Tangible Products. Proceedings of the 1st international conference on Tangible and Embedded Interaction (TEI), 155-158.

[18] Hinske, S., and Lampe, M. 2007. Semantic Mapping of Augmented Toys between the Physical and Virtual World. Tangible User Interfaces in Context and Theory, Workshop at CHI'07, San Jose, USA.

[19] Hinske, S., Lampe, M., Magerkurth, C., and Röcker, C. 2007. Classifying Pervasive Games: On Pervasive Computing and Mixed Reality. In: Magerkurth, C., Röcker, C., Eds. Concepts and technologies for Pervasive Games - A Reader for Pervasive Gaming Research. Vol. 1, Shaker.

[20] Hinske, S., and Lampe, M. 2007. Augmented toy environments: shareable tangible user interfaces for edutainment, presented at the Shareable Interface Workshop at Open University, DOI=http://www.vs.inf.ethz.ch/publ/papers/hinskeshareable07.pdf

[21] Ishii, H. and Ullmer, B., 1997, Tangible Bits: Towards Seamless Interfaces between People, Bits and Atoms. In Proceedings of Conference on Human Factors in Computing Systems (CHI '97), ACM, Atlanta, 234-241.

[22] Jacob, R., Deligiannidis, L., and Morrison, S. 1999. A Software Model and Specification Language for Non-WIMP User Interfaces. ACM Transactions on Computer-Human Interaction, 6, 1, 1-46.

[23] Kafai, Y. 2003. Children designing software for children what can we learn? Small Users - Big Ideas: Proceedings of Interaction Design and Children 2003 conference, New York: ACM Press, 11-12.

[24] Lampe, M., and Hinske, S. 2007. The Augmented Knight's Castle - Integrating Mobile and Pervasive Computing Technologies into Traditional Toy Environments. In Magerkurth, C., Röcker, C., Eds. Concepts and technologies for Pervasive Games - A Reader for Pervasive Gaming Research. Vol. 1, Shaker.

[25] Levy, R.C., and Weingartner, 2003. R.O. The Toy and Game Inventor's Handbook, Alpha, ISBN 978-1592570621.

[26] Malone, T.W., and Lepper, M.R. 1987. Making Learning Fun: A Taxonomy of Intrinsic Motivations for Learning. In Snow, R.E. and Farr, M.J. Eds. Aptitude, Learning and Instruction. Volume 3: Conative and Affective Process Analyses. Hillsdale, NJ: Erlbaum, 223-253.

[27] Markopoulos, P., Read, J., Hoysniemi, J., and MacFarlane, S. 2007. Child computer interaction: advances in methodological research. Introduction to the special issue of cognition technology and work, Online First, Springer.

[28] Mattern, F. 2001. The Vision and Technical Foundations of Ubiquitous Computing. Upgrade, Vol. 2, No. 5, 2-6. 
[29] Morris, M.R., Cassanego, A., Paepcke, A., Winograd, T., Piper, A. M., and Huang, A. 2006. Mediating Group Dynamics through Tabletop Interface Design. In IEEE Computer Graphics and Applications, Vol. Sep/Oct, 65-73.

[30] Norman, D. and S. Draper. 1986. User Centered System Design. L. Erlbaum \& Associates, Hillsdale, NJ.

[31] Pagulayan, R. J., Keeker, K., Wixon, D., Romero, R., and Fuller, T. 2002. User-Centered Design in Games. In Jacko, J. and Sears, A. Eds. Handbook for Human-Computer Interaction in Interactive Systems. Mahwah, NJ: Lawrence Erlbaum Associates, 883-906.

[32] Prensky, M. 2001. Digital Game-Based Learning, New York: McGraw-Hill.

[33] Rogers, Y., Scaife, M., Gabrielli, S., Smith, H., and Harris, E. 2002. A conceptual framework for mixed reality environments: designing novel learning activities for young children. In Presence: Teleoper. Virtual Environments, Vol. 11, No. 6, 677-686.

[34] Rogers, Y., Taylor, I., Stanton, D., O Malley, C., Corke, G., Gabrielli, S., Scaife, M., Harris, E., Phelps, T., Price, S., Smith, H., Muller, H., Randell, C., and Moss, A. 2002. Things aren't what they seem to be: innovation through technology inspiration. In Proceedings of Designing Interactive Systems 2002, 1-11.

[35] Schaller, D. 2006. What Makes a Learning Game? DOI=http://www.eduweb.com/schaller-games.pdf

[36] Schmidt, A. 2000. Implicit Human Computer Interaction Through Context. In Personal and Ubiquitous Computing, 4, 2/3.

[37] Schraefel, M.C., Hughes, G., Mills, H., Smith, G., and Frey, J. 2004. Making Tea: Iterative Design Through Analogy. In Proceedings of Designing Interactive Systems 2004.

[38] Shaer, O., Leland, N., Calvillo-Gamez, E.H., and Jacob, R.J.K. 2004. The TAC Paradigm: Specifying Tangible User Interfaces, Personal and Ubiquitous Computing, Vol. 8, No. 5, 359-369.

[39] Sharlin, E., Watson, B. A., Kitamura, Y., Kishino, F., Itoh, Y. 2004. On Tangible User Interfaces, Humans and Spatiality, In Personal and Ubiquitous Computing, Special Issue on Tangible Interfaces in Perspective.

[40] Shwe, H. 1999. Smarter Play for Smart Toys: The Benefits of Technology-Enhanced Play, Zowie Intertainment White Paper 3208.

[41] Soloway, E., M. Guzdial and K. Hay. 1994. LearnerCentered Design: The Challenge for HCI in the $21^{\text {st }}$ Century. Interactions. 1, 2, 36-48.

[42] Stapleton, C. B., Hughes, C. E. and Moshell, J. M. 2002. Mixed reality and the interactive imagination. Presented at
First Swedish-American Workshop on modeling and simulation (SAWMAS 02).

[43] Stapleton, C. B., Hughes, C. E. and Moshell, J. M., Micikevicius, P., and Altman, M. 2002. Applying Mixed Reality to Entertainment. In IEEE Computer, vol. 35, 122124.

[44] Stringer, M., Rode, J.A., Toye, E.F., Blackwell, A.F. 2004. Iterative Design of Tangible User Interfaces. In Proceedings of the 2004 conference on Interaction design and children: building a community, 11-18.

[45] Thackara, J. 2000. Edge Effects: The Design Challenge of Pervasive Computing interactions, In Proceedings of Conference on Human Factors in Computing Systems (CHI'00), 199-200.

[46] Terrenghi, L., Fritsche, T., Butz, A. 2006. The EnLighTable: Design of Affordances to Support Collaborative Creativity. In Proceedings of Smart Graphics Symposium.

[47] Terrenghi, L. 2007. Designing Hybrid Interaction through an Understanding of the Affordances of Physical and Digital Technologies. Tangible User Interfaces in Context and Theory, Workshop at CHI'07, San Jose, USA.

[48] Ullmer, B., and Ishii, H. 2001. Emerging frameworks for Tangible User Interfaces. In Carroll, J.M. Ed. HumanComputer Interaction in the New Millennium, AddisonWesley, New York, 579-601.

[49] Universal Design for Play Guidelines. 2004. DOI=http://letsplay.buffalo.edu/UD/ud_toy_features_1.htm

[50] Vandewater E. A., Shim Mi-suk, Caplovitz A. G. 2004. Linking obesity and activity level with children's television and video game use. In Journal of Adolescence, 27, 71-85.

[51] Weiser, M. 1991. The Computer for the 21st Century. In Scientific American Special Issue on Communications, Computers, and Networks, September 1991.

[52] Winograd, T. 2002. Interview on Understanding and Conceptualizing Interaction. In Preece, J., Rogers, Y., and Sharp, H. Eds. Interaction Design. Beyond Human-Computer Interaction, 89-91.

[53] Wren, C.R., and Reynolds, C.J. 2004. Minimalism in Ubiquitous Interface Design. In Personal and Ubiquitous Computing Journal, Vol. 8, 370-373.

[54] Ye, Z. 2005. User-Centered Design in the Age of Game Design Paradigm Change, DOI=www.yebrothers.com/documents/UCDGameDesign2.pdf

[55] Ye, Z. and Ye, D. 2004. HCI and Game Design: From a Practitioner's Point of View. DOI= http://www.yebrothers.com/documents/HCIGAMEDESIGN.pdf 